\title{
Childbirth and New Omics Sciences: an Ecological Perspective
}

\author{
Antonio Ragusa* and Alessandro Svelato \\ Department of Obstetrics and Gynecology, Massa Carrara General Hospital, Italy
}

Submission: December 25, 2017; Published: January 17, 2018

*Corresponding author: Antonio Ragusa, Dipartimento Materno Infantile U.O.C. di Ginecologia e Ostetricia Viale Mattei, Marina di Massa, Italy, Tel: +39 3355726903; Email: antonio.ragusa@gmail.com

\begin{abstract}
Epigenetics can be defined as the study of the changes in the genetic expression that do not involve changes in the inheritable DNA sequence. The epigenetic mechanisms can cause the characteristic phenotypic traits of the parents to be transmitted to their children, both directly and indirectly. During the first moment of life, numerous nucleotidic sequences are activated, and the way in which this takes place can have longterm consequences. Delayed or anticipated clamping of the umbilical cord at birth, the administration of medication, such as synthetic oxytocin or Fentanest (fenantyl $囚$ ) during labour, can have long-term effects on the health of both the mother and newborn child. Being informed regarding epigenetic mechanisms also enables to carry out positive actions, such as reducing the number of resorts to Caesarean sections for trivial reasons. This enables the newborn to acquire the mother's vaginal microbiome. Support breastfeeding and to modulate maternal nutrition, in order to programme better eating habits in newborns and adults, could be a useful strategy in the reduction of obesity and diabetes in many countries around the world.
\end{abstract}

\section{Mini Review}

We recently learned that we are not predetermined, at least not completely. Our destiny depends on our interaction with the environment, on the composition and expression of the DNA of the germ cells of our parents, but also on the epigenetic modifications that the latter undergo [1]. We recently discovered that the environment can change the expression of our DNA. Epigenetics, a word used for the first time by Waddington in 1957, can be defined as the study of the changes in gene expression that do not cause changes in the sequence of heritable DNA. It is simple to understand the meaning of epigenetics, considering that each and every cell in our body have the same nucleotide sequence, and yet each cell becomes something different. We can understand how the phenotypic expression differences depend on the context in which the genes are expressed, and not only on the nucleotide sequence. There are numerous epigenetic mechanisms, the most important being the methylation processes and those that use small molecules of non coding RNA, which are synthesized by DNA that was once known as/called junk DNA, which, until a few years ago, had no known function. The first studies on this topic demonstrated how, if foetuses with low weight, well suited to the resource-poor environment of the uterus, are, after birth, in an environment full of rich in food resources, have a dramatically higher tendency to develop cardiovascular illnesses compared to children born with a normal weight [2].

Even if the idea concept of programming was discovered before prior to Barker, his epidemiological studies at the end of the 1980s were the ones that led to the clear formulation of the theory according to which events in foetal life can have a longterm effect on the risk of developing metabolic illnesses. Using a cohort of men aged 64, all born in Hertfordshire (UK), Barker identified a relationship between low weight at birth, high systolic blood pressure and increase in cardiovascular deaths. Using the same cohort of men, he also demonstrated that there is a connection between low weight at birth, reduced tolerance to glucose and increase in insulin-resistance.

The epigenetic mechanisms may cause the characteristic phenotypic traits of the parents to be transmitted to offspring both directly, by means of the micro RNA, as well as indirectly. During the first minutes after birth, numerous nucleotide sequences are activated and deactivated, and the way in which this takes place will have long-term consequences. This demonstrates that the responsibility of obstetricians is not only limited to the moment 
of birth alone. A fascinating example is the effect that changing the time of clamping of the umbilical cord during birth has on the newborn. In a randomized study, Swedish researchers discovered that children of four years old on which delayed clamping $(\geq 180$ seconds after birth) was carried out, above all boys, had better mobility and social skills compared to those who underwent early clamping ( $\leq 10$ seconds after birth) [3]. This indicates that the optimization of CC time can have a long-term effect on neurological development, mostly in male newborns. Another example regards the administration of medication during labour. The more foetuses are exposed to synthetic oxytocin (synOT) or to fentanyl used in epidural anesthesia during labour, the more difficulty they have at birth to suckle and in reaching, during the first hour after birth, the mother's breast [4]. Oxytocin, defined as "facilitates species propagation", is a peptide that has a centralized role in the determining of relational adaptation processes in mammals [5]. Women who are given less synOT intrapartum are more exclusively breastfeeding at 2 months postpartum. Moreover, higher synOT doses are associated with greater depressive, anxious, and somatization symptoms $[6,7]$. Another paradigm that we are slowly starting to leave behind and move away from, is the one that considered microorganisms exclusively as enemies of eukaryotic organisms. Billions of micro-organisms live together in our bodies. More of the cells that make up our body are not human, we live, in fact, with several hundred grams of E. coli, germs that live inside our intestines. Some bacteria found in our digestive system are fundamental for us to metabolize some essential nutrients. What are we? A Super-organism (holobiont) made up of about 10 trillion cells deriving from sperm and egg cell, expressing about 23,000 human genes, and about 100 trillion microbe cells, which express 3,000,000 microbial genes [8]. If we then take into consideration the nucleotide sequences of viral origin, preserved inside our code, sequences of which the placenta is the most representative source, we can then understand how close we are to a complete cultural and medical revolution [9].

Until a few years ago it was thought that the uterus was a sterile environment [10]. Recent studies suggest that the placenta contains a small amount of bacteria. In 2014 a team led by Kjersti Aagaard, found distinct microbial signatures of placentas from 320 healthy human pregnancies [11]. A recently published study suggests that these placental microbes may begin to colonize the human intestine shortly before birth [12]. The results are still controversial, some researchers claim that microbes might be the result of a contamination of the biological samples [13].

The maternal diet can also have an impact on the placental microbiome. An adequate bacterial colonization, which probably starts during life in the uterus and definitely continues in the first moments after birth, is fundamental, since disturbances in this process are connected to the development of allergic reactions, type 1 diabetes and autoimmune diseases [14].

The most important factor in determining the composition of the human microbiome of adults is, however [15] diet. Changing eating habits during pregnancy could have an effect on the transmission of a metabolome that reduces the possibility of illnesses in adult life. It was recently demonstrated that a higher consumption of fruit during pregnancy results in Cognitive Enhancement in Infants [16].

How can we interact with these processes that we are beginning to know about during pregnancy and birth? (Figure 1). Let's take a look at one of these interesting topics - the use of the Caesarean section and diet.

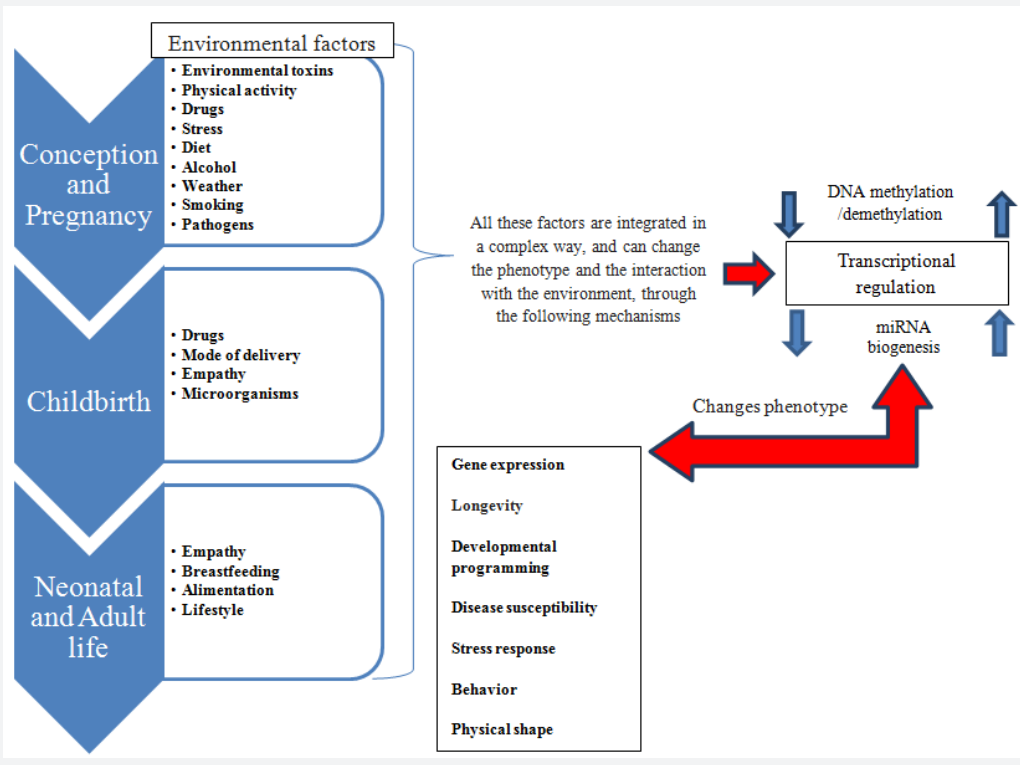

Figure 1: Environmental factors and epigenetic modifications.

Diverse environmental factors can have an influence during the lifetime of an individual, causing changes in the main epigenetic mechanisms: DNA methylation/demethylation and miRNA biogenesis. These mechanisms lead to a change in phenotype that involves an adaptation to the environment, and ultimately to a continuous modification in the response of the organism. 
The Caesarean section can, in fact, actually reduce maternal and perinatal mortality and morbidity if carried out as a result of precise medical indications. However, there is no scientific evidence to prove the benefits a Caesarean section on mothers and newborns when carried out without any clinical justification [17]. On the contrary, women who undergo a Caesarean section, are more subject to a higher rate of:
a. Maternal, death and morbidity;
b. Peripartum hysterectomy;
c. Subsequent hospitalizations during puerperium;
d. Embolism of the amniotic fluid;
e. Accretism of the placenta in successive pregnancies.

Babies born by Caesarean section are more subject to $[18,19]$ :

a. Peri-Caesarean iatrogenic lacerations;

b. Respiratory morbidity;

c. Worse cardiovascular adaptation;

d. Reduced ability to be breast fed;

e. Anaemia; l. Asthma;

m. Laryngitis;

n. Gastroenteritis;

o. Ulcerative colitis;

p. Celiac disease;

q. Infections of the lower respiratory tract;

r. Juvenile idiopathic arthritis;

s. Death;

t. Obesity;

u. Type 1 diabetes;

v. Metabolic syndrome;

w. Cancer;

x. Leukemia.

This last increased risk - leukemia - can probably be explained by the fact that the stress of birth predisposes newborn babies to improve the clearance capacity of pre-neoplastic cells by means of a complex biochemical and immune mechanism (Figure 2).

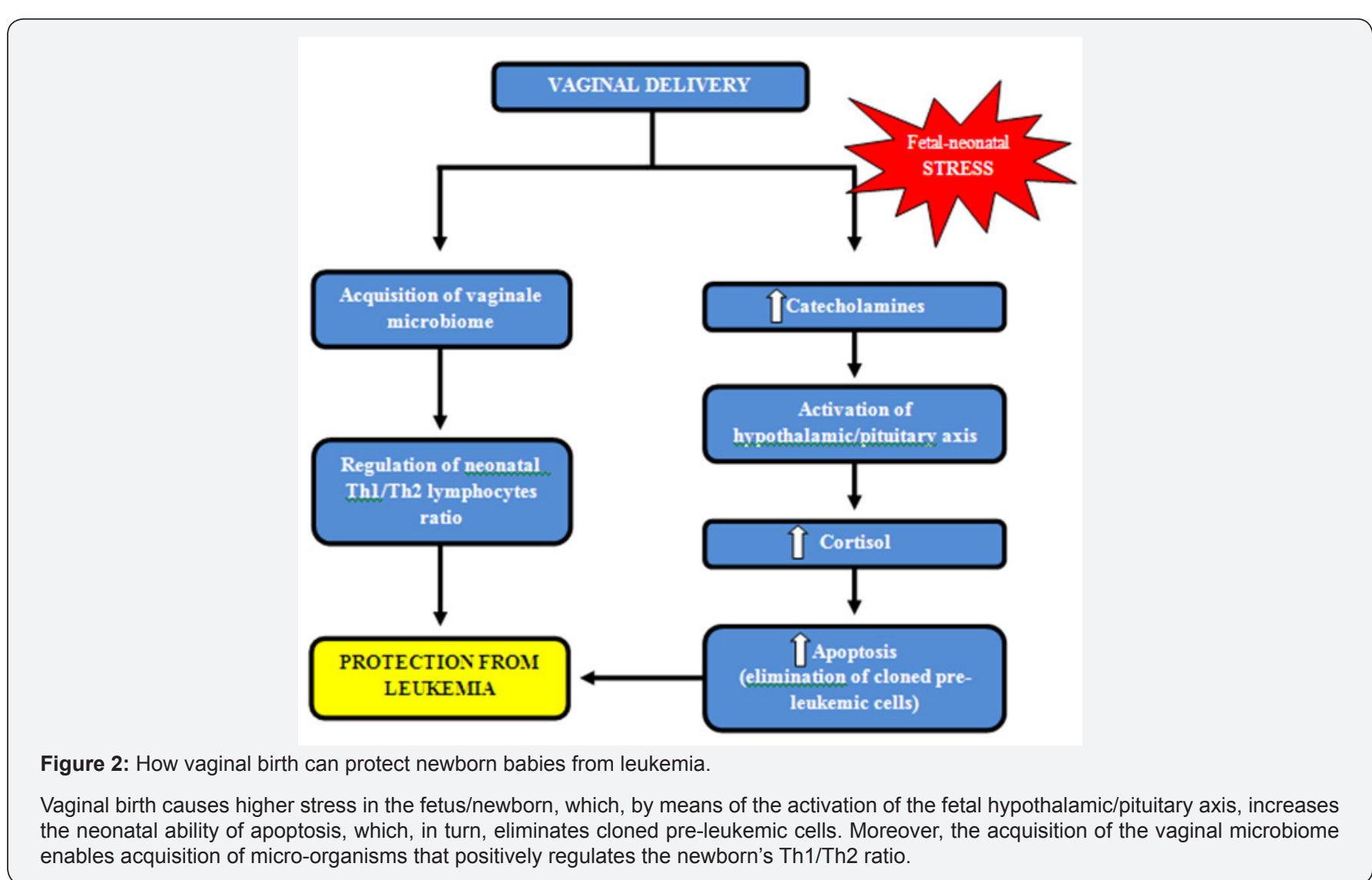

Lastly, diet has an important role in many aspects of health, and dietary imbalances are crucial in the genesis of chronic diseases such as cardiovascular illnesses, obesity, diabetes and cancer. The hypothesis that epigenetic mechanisms can connect nutritional imbalances during pregnancy, with diseases and their risk in adult life, has, in recent years, become ever more 
accepted by many scientists. Surprisingly, almost all epigenetic mechanisms respond effectively to compound environmental signals, among which diet. Diet - in particular during pregnancy enables to modulate the creation and maintenance of epigenetic of marks, thus influencing gene expression and, therefore, the risk of illness or good health in the future. A striking example comes from the study regarding the ontogeny of human sense of smell.

In 1995, JA Mennella took samples of amniotic fluid from 10 pregnant women subject to routine routine amniocentesis [20]. About 45 minutes before the procedure, five women took placebo capsules, while the other five took capsules with essential oil of garlic. The samples were then evaluated by a sensory panel of adults. The smell of the amniotic fluid of four of the five women who had taken le garlic capsules was judged to contain garlic, compared to the samples of the women who had taken the placebo capsules. This shows that the ingestion of garlic by pregnant women significantly changes the smell of their amniotic fluid. After this study, numerous experimental confirmations have sanctioned the uterine ontogeny of human flavours and tastes.

Initiatives regarding health often deal with childhood obesity, in part by encouraging a healthy diet during the first years of life. However, science shows us that children naturally prefer higher levels of sweetness and savoury tastes and tend to refuse lower levels of bitter tastes compared to adults. The good news is that sensory experiences develop early in life and can be changed. Mothers who have a healthy diet will be able to give their children a good start, because tastes are transmitted from the mother's diet to the amniotic fluid and breast milk [21].

Another promising area of research regarding maternal nutritional modulation, with the aim of having a positive impact on the neonatal/adult health of the unborn child, can be seen in the use of probiotics, prebiotics and symbionts. The use of these substances by mothers during pregnancy has already demonstrated in being able to reduce infections and neonatal allergies [22].

\section{References}

1. Portha B, Fournier A, Kioon MD, Mezger V, Movassat J (2014) Early environmental factors, alteration of epigenetic marks and metabolic disease susceptibility. Biochimie 97: 1-15.

2. Barker DJ (1995) Fetal origins of coronary heart disease. BM] 311(6998): 171-174.

3. Andersson O, Lindquist B, Lindgren M, Stjernqvist K, Domellöf M, et al. (2015) Effect of Delayed Cord Clamping on Neurodevelopment at 4 Years of Age: A Randomized Clinical Trial. JAMA Pediatr 169(7): 631638.

4. Brimdyr K, Cadwell K, Widström AM, Svensson K, Neumann M, et al. (2015) The Association Between Common Labor Drugs and Suckling When Skin-to-Skin During the First Hour After Birth. Birth 42(4): 319 328.
5. Lee HJ, Macbeth AH, Pagani JH, Young WS $3^{\text {rd }}$ (2009) Oxytocin: the great facilitator of life. Prog Neurobiol 88(2): 127-151.

6. Gu V, Feeley N, Gold I, Hayton B, Robins S, et al. (2016) Intrapartum Synthetic Oxytocin and Its Effects on Maternal Well-Being at 2 Months Postpartum. Birth 43(1): 28-35.

7. Cardaillac C, Rua C, Simon EG, El-Hage W (2016) Oxytocin and postpartum depression. J Gynecol Obstet Biol Reprod 45(8): 786-795.

8. Bosch TCG, Miller DJ (2016) The Holobiont Imperative. Perspectives from Early Emerging Animals. Springer, Vienna, Australia.

9. Taylor J (2016) A virus forms the placenta, causes fetal tolerance, and makes muscular males. EvMed Review.

10. Maynard CL, Elson CO, Hatton RD, Weaver CT (2012) Reciprocal interactions of the intestinal microbiota and immune system. Nature 489(7415): 231-241.

11. Aagaard K, Ma J, Antony KM, Ganu R, Petrosino J, et al. (2014) The placenta harbors a unique microbiome. Sci Transl Med 6: 237ra65.

12. Collado MC, Rautava S, Aakko J, Isolauri E, Salminen S (2016) Human gut colonisation may be initiated in utero by distinct microbial communities in the placenta and amniotic fluid. Sci Rep 6: 23129.

13. Salter SJ, Cox MJ, Turek EM, Calus ST, Cookson WO, et al. (2014) Reagent and laboratory contamination can critically impact sequencebased microbiome analyses. BMC Biol 12: 87.

14. Sekirov I, Russell SL, Antunes LC, Finlay BB (2010) Gut microbiota in health and disease. Physiol Rev 90(3): 859-904.

15. Voreades N, Kozil A, Weir TL (2014) Diet and the development of the human intestinal microbiome. Front Microbiol 5: 494.

16. Bolduc FV, Lau A, Rosenfelt CS, Langer S, Wang N, et al. (2016) Cognitive Enhancement in Infants Associated with Increased Maternal Fruit Intake During Pregnancy: Results from a Birth Cohort Study with Validation in an Animal Model. EBioMedicine 8: 331-340.

17. Betran AP, Torloni MR, Zhang JJ, Gülmezoglu AM, WHO Working Group on Caesarean Section (2016) WHO Statement on Caesarean Section Rates. BJOG 123(5): 667-670.

18. Black M, Bhattacharya S, Philip S, Norman JE, McLernon DJ (2015) Planned Cesarean Delivery at Term and Adverse Outcomes in Childhood Health. JAMA 314: 2271-2279.

19. Kristensen K, Henriksen L (2016) Cesarean section and disease associated with immune function. J Allergy Clin Immunol 137: 587590.

20. Mennella JA (2014) Ontogeny of taste preferences: basic biology and implications for health. Am J Clin Nutr 99: 704S-711S.

21. Trout KK, Wetzel-Effinger L (2012) Flavorlearning in utero and its implications for futureobesity and diabetes. Curr Diab Rep 12(1): 6066.

22. Kalliomäki M, Salminen S, Arvilommi H, Kero P, Koskinen P, et al. (2001) Probiotics in primary prevention of atopic disease: a randomised placebo-controlled trial. Lancet 357(9262): 1076-1079. 
Your next submission with Juniper Publishers will reach you the below assets

- Quality Editorial service

- Swift Peer Review

- Reprints availability

- E-prints Service

- Manuscript Podcast for convenient understanding

- Global attainment for your research

- Manuscript accessibility in different formats

( Pdf, E-pub, Full Text, Audio)

- Unceasing customer service

Track the below URL for one-step submission https://juniperpublishers.com/online-submission.php 